\title{
A STUDY ON UNDERSTANDING THE SOCIAL INTERACTION ARISES FROM URBAN PARK ENVIRONMENT THROUGH DIFFERENT INTERACTION TYPES; Related to Diyatha, Katubedda and Kelimadala urban parks in Colombo district
}

\author{
LOKULIYANA, C.K. ${ }^{1} \&$ RATNAYAKE, G.R. ${ }^{2}$ \\ 1,2Department of Town \& Country Planning, Faculty of Architecture, University of Moratuwa, Moratuwa, Sri Lanka \\ 1Chathrikakawmadi123@gmail.com
}

\begin{abstract}
In 1990s, the decrement of non-built up areas due to urbanization in Sri Lanka cause for reducing the quality of life and emerging of social issues by interruption of human interaction with the busiest monotonous life styles. The urban beautification projects like urban park concept was introduced to achieve the Sri Lankan sustainable vision by 2030 by developing those spaces as social spaces for the purpose of community gathering and interaction. With this emerging concept, there is no such consideration or the research regarding identification of social interaction types in park to increase the park planning potentials in Sri Lanka by achieving the social sustainability of the place via social interaction. Above mentioned objective of the research is overcome through the theoretical framework of "social network theory" by understanding the actor and user types in the urban park context in Sri Lanka especially for Colombo district which have dissimilarity of availability of design characteristics. The methodology of the research is consisted with onsite observations and questionnaire surveys under mixed method approach. There are different intensity of social interactions were happened in three selected parks, from these the social interactions highly occurred among adults-adults user category and the least social interaction can be seen among children-younger user category in three parks and the highest expected factor for interaction is accessibility rather than consideration other factors. Additionally, provide shady greenery areas with multidiverse activities for all user and actor categories based on respondents' comments will be needed to consider in increasing the future planning potentials to achieve social sustainability of the urban parks via social interaction in Sri Lanka.
\end{abstract}

Keywords: Urban parks; social interaction; social network; social sustainability

\section{Introduction}

The revolution of urbanization in cities of developing countries deteriorates the liveability and the sustainability (Kasarda \& Rodineli, 1990). The issues occurred due to urbanization can be overcome through the sustainable city development which is considered as an integral part in recent decades (Pacion, 2009). Social sustainability is an important component in sustainable development and social interaction is one of the factor that can be formatted the social sustainability (Dempsey et al., 2012). Meeting opportunities are important for the development of local communities and their interactions (Volker et al., 2007). Therefor the reduction of social interactions may cause for occurrence of depressive symptoms, isolation, hopelessness as well as deteriorates the quality of life (Abada et al., 2007). Social interaction begins with the space which has proper facilities and design characteristics (Poodeh \& Vali , 2014). Recreational facilities like urban green spaces which generate social interactions among people (Volker et al., 2007). The green open spaces like urban parks provide wider range of opportunities to users by identifying their demographic and social parameters such as types of interactions, usage pattern and their expectations (Konau, 2016). But there are lack of understanding and problems in measuring social usage and interaction among different users and actors in recreational green open space environment (Manning, 2011). This situation can be changed through spatial planning by providing interaction opportunities in urban park planning (Rafiyan, 2002). "Planning is for people" so the core of the urban planning is to make interconnection between people and urban places. Therefore Understanding of human interactions, preferred patterns of users in urban parks provide essential platform for urban park planning and designing potentials (Faros \& Ahern, 1995). 
When considering Sri Lankan context, Sri Lankan cities have been rapidly expended in 1990 s especially in Colombo district due to the urbanization effect. Non- built up area is highly reduced due to the higher level of urban expansion. Due to the urbanization in recent years, the urban community is suffering from overall stress attached to urban life in Sri Lanka (Haatig \& Staas, 2007). As well as some of social issues such as depression, isolation immense human suffering in Sri Lanka due to urbanization occurred because of interruption of social interactions (Hettige, 2013). The urban park concept were introduced to overcome this situation and balanced inclusive green growth in Sri Lanka to achieve the sustainable vision by 2030 (Munasinghe, 2004). So the urban green open spaces like urban parks are essential component of the city and social infrastructure which defines the quality of life of the urban population in Sri Lanka. $30 \%$ of users use the urban parks for socialization purposes such as interactions, walking and relaxation (Konau, 2016). So the urban parks have greater potentials to generate interactions within urban community in the urban context. But the planning failures are the emerging problem in green open spaces in Sri Lanka especially in Colombo district. The survey analysis of the urban parks in Colombo proves that there are lack of social activities, events for social gathering and making interactions with actor and user categories (Konau, 2016). Also these issues are diffusely impacted for weaken of social interaction among urban community. So the weaken of social interactions can be affected for the instability of the social sustainability of the urban places. Sri Lankan cities like Colombo and its suburban's main focus is to development of economic and physical dimensions rather than social dimension (Bandara, 2013). Therefore the research has not been researched yet and fill the above knowledge gap.

So the main objective of the research is to understand about different social interaction types in urban parks to increase the park planning potentials in Sri Lanka which can be achieved through answering the research questions of what are the types of social interactions in urban parks and investigate different preferred factors of users for social interaction within urban park context in three selected parks of Colombo district in Sri Lanka.

\section{Literature Review \& Similar Studies}

The evolution of urban park has a long history which had begun from United States. That evolution was responded to more on social problems like lack of integration and expressed the various ideas about nature (Galen \& Michael, 2004). The urban parks are the inclusive places which can possibly stimulate the community development and social interaction (Annerstedt et al., 2013). In Sri Lanka also main purpose of creation of urban parks is for developing opportunities meet, talk, rest, interact with people in comfortably and publically within urban areas (Hettiarachchi \& Silva, 2016).

Individuals are considering as social being, there is an importance of making interactions because it highlighted the social sustainability and quality of life of the people (Puthnam, 2000). So the essential condition of the urban parks be considered that there should be social interaction happen in them (Rahnemai, 2007). However the Appearance and the physical condition of the urban parks can encourage either permitted or prohibited behaviours and the social interactions (Kelling \& Wilson, 1982).

The theoretical understanding which is incorporated to the study provides better guidance to the analysis and finding section of the research. Place making concept is applicable for the planning and designing of the urban spaces. The sociability, image and comfort, uses and activities and accessibility are the important elements which increase quality an urban place according to place making concept (PPS, 2007). Recently, place making concept is linked with green space planning incorporates with functional uses (Chillers \& Timmermans, 2014). The main key theory used in the study for evaluating the interaction is social network theory. The theory was introduced by sociologists in 1950s (Barner, 1954; Mitchell, 1969). In this theory, it describes the relationship between nodes (actors) and users. Social networks are starting from simple interactions with acquaintance to complex interaction with 
strangers. It is useful to understand the types of interaction within a specific spatial scale. Therefor, in the research this theory is applicable for social characteristics auditing and interaction identification (checklist protocol method in behavioural mapping) in selected parks which occurs between users (children, youngers, adults, seniors) with actors (individuals, dyads and groups). Socio-cultural theory was explained that the higher functioning interactions of the urban places occurred through provision of socio-cultural opportunities (Vygotsky, 1978).

Many scholars had done many researches about urban parks and the social interactions. Also there is a need of study based on categorization of types of actors' interactions as a matrix of social interaction (Pipi, 2014). The park usage of the different actor types have to be investigated in different contexts but not the special focus is paying for Sri Lankan context (Konau, 2016). According to understanding of previous research work, this research is investigated about different social interaction types in urban parks to increase the park planning potentials in Sri Lanka by using mixed method approach for the three selected urban parks in Colombo. Further the research is applied social network theoretical understanding which is significance from previous researches.

\section{Research Design}

\subsection{CASE STUDY SELECTION}

There should be a systematic way for selecting the case studies to achieve research objective of understanding about different social interaction types in urban parks to increase the park planning potentials in Sri Lanka. So Ballester, Morata \& Olmos, (2001) ; classification of identified availability of park components in Mexico city are applied for the selecting suitable case studies for the research. Through understanding of the previous research work incorporate them into the UDA classification of urban parks in Sri Lanka according to weighted scoring method. The weights are giving according to importance of components availability from the understanding of literature reviews. Weighted scoring method derives three parks with dissimilarity of availability in above mentioned components with the ranking levels of 1 (Diyatha Uyana), 4 (Kelimadala) and 7 (Katubedda park) in Colombo district for the study purpose with the availability of various types of interactions.

\subsection{Data Collection \& Analysis Methods}

Data collection method of the study is based on onsite observations and questionnaire surveys. According to understanding of previous similar research work play areas, pathways for walking and cycling, exercise areas, seating areas, naturalistic areas and food stole areas are the selected sub locations within the parks for the observations. These selected sub areas are happened more social interactions with actor and user groups which is understanding through preliminary site observations. Initially reordered the interactions happened with user and actor categories by using protocol checklist method in behavioural mapping by dividing interactions into three levels with social network theoretical understanding. This method is most relevant method for observing the user and actor interaction patterns (Cosco et al., 2010). Questionnaire survey is targeted to 165 sample respondents who are selecting from random sampling method while they engaging their leisure activities. Questionnaire survey is used for enrich the data gathered from onsite observations during the study.

Data analysis method of the study is aimed for mixed method approach which utilized the qualitative and quantitative techniques. Those are included descriptive statistical methods and protocol checklist method of behavioural mapping by using social network theory.

\section{Findings and Results}

The find and results section is consisted with answer the two research question of the study which are what are the types of social interactions happened in three selected parks according to the social 
network theoretical background and investigate different preferred factors of users for social interaction based on data collected through onsite observations and questionnaire surveys.

According to overview of the summery of observations in checklist protocol method of behavioural mapping incorporates with social network theory derived that the total observed interactions in three parks were 1359, it consisted with 189 (12.91\%) from Katubedda, 233 (19.14\%) in Kelimadala and 937 (64.22\%) from Diyatha Uyana park respectively in weekdays and weekends. So these results proved that the highest number of social interactions are in Diyatha Uyana 937 (64.22\%) from the total observations and least social interactions are in Katubedda park 189 (12.91\%).

Table 1, Summary of the observations in three parks

(Source: Compiled by author, 2019)

\begin{tabular}{|c|c|c|c|}
\hline Observations & $\begin{array}{l}\text { Katubedda walkway } \\
\qquad \& \text { lake park }\end{array}$ & $\begin{array}{l}\text { Kelimadala } \\
\text { urban park }\end{array}$ & $\begin{array}{c}\text { Diyatha Uyana urban } \\
\text { park }\end{array}$ \\
\hline \multirow{2}{*}{$\begin{array}{l}\text { Total observed } \\
\text { user interactions }\end{array}$} & 189 & 233 & 937 \\
\hline & $12.91 \%$ & $19.14 \%$ & $64.22 \%$ \\
\hline \multirow{2}{*}{ Male } & 122 & 113 & 496 \\
\hline & $64.55 \%$ & $48.49 \%$ & $52.93 \%$ \\
\hline \multirow{2}{*}{ Female } & 67 & 120 & 441 \\
\hline & $35.44 \%$ & $51.50 \%$ & $47.06 \%$ \\
\hline
\end{tabular}

Accordingly social network theory, there are actors (nodes) and users who make their interactions which are useful to understand how the social interactions occur within the social structures through observation data.

Table 2, Social interactions by levels according to social network theory

(Source: Compiled by author, 2019)

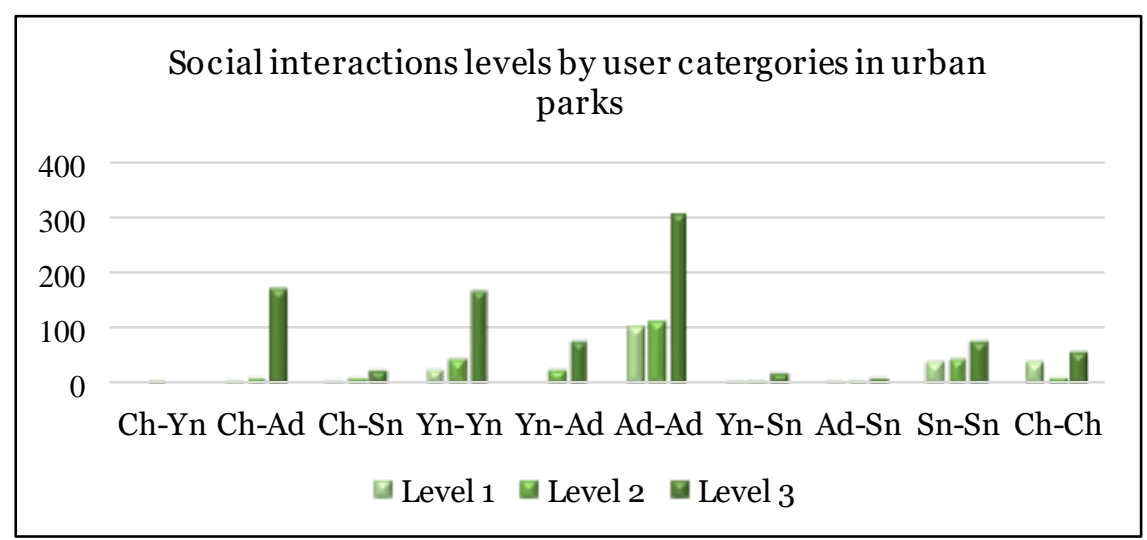

Three interaction levels highly occurred among adults-adults (age 18-65 yrs.) 513 (37.74\%) from the total observed social interactions. The least total interactions by the user categories can be seen among children (age below 12 yrs.) -youngers (age 12-17 yrs.) which has the interactions of 3 (0.22\%). Observed highest level one interactions((Short term superficial contacts among people who do not recognize each other (strangers) greet, wave, smile (less than $1 \mathrm{~min}$ ) occurred among adults-adults with 100 (48.54\%) from total level one interactions. The second level ((occurs short time period with unacquainted or familiar persons who meet randomly informal talks, greeting, taking pictures, carrying pets (1- $15 \mathrm{~min})$ ) 107 (43.49\%) and third level ((long term contacts with close friends, lovers or relatives chatting, playing, sitting, dining, taking pictures (more than $15 \mathrm{~min}$ )) 306 (33.73\%) 
observed interactions also highly occurred among adults-adults. The lowest interactions of level one are represented among children (below 12 yrs.) - senior citizens (age above 65 yrs.) and youngers senior citizens (age above 65 yrs.) 1(0.48\%) in all the observed sub locations of three parks. Lowest level two and three interactions are occurred respectively among youngers and senior citizens which is 2 (0.81\%) and among adults-seniors 11(1.21\%).

When consider about the actor types, interaction occurred with individuals and interactions occurred with more than one user (dyad or groups) can be elaborated as follows based on observations.

Table 3, Social interactions by actor types according to social network theory

(Source: Compiled by author, 2019)

All selected three urban park locations

\begin{tabular}{|c|c|c|}
\hline Total Interactions $=\mathbf{1 3 5 9}$ & \\
\hline Social interactions by levels & With individuals & $\begin{array}{c}\text { With more than one user } \\
\text { (dyad or groups) }\end{array}$ \\
\hline Level 1 & 58 & 150 \\
\hline Level2 & 249 & 186 \\
\hline Level3 & 216 & 686 \\
\hline
\end{tabular}

Level one interactions 58 (4.26\%) are occurred within individuals and 150 (11.03\%) interactions are occurred with more than one user (dyad or groups). Level two interactions are represented 63 (4.63\%) with individuals and 186 (13.68\%) are occurred among more than one user. Level three interactions highly occurred within dyad and groups which has 686 (50.47\%) \& individual interactions are 216 (15.89\%). The total three levels interaction are derived $61.52 \%$ have interacted with dyad or with groups. Accordingly, results are interpreted that Asian country like Sri Lankan community like more to interact with dyads and groups rather be with individuals because culturally well organized activities and functions of the urban parks provide more opportunities for interacting among group of users according to socio-cultural theory.

The general demographic characteristics of the respondents who were engaging to questionnaire survey included 165 total sample from that $56.6 \%$ are males and $42.4 \%$ are females in three parks. Most of the respondents who were involved to the survey within the age category of 18-65 yrs. (Adults). When comparing to the per capita monthly income, most of them are not employees 72 (43.6\%).

Based on the questionnaire survey in order to frequency analysis different preferred factors for interactions are categorized into eight. From those the highest preferred factor is accessibility with the frequency values of 10 (50\%), 35 (78\%), 66 (66\%) in three parks. Place making concept is derived that image and comfort, accessibility are the most important characters which increase the social interaction in urban places. Therefore the accessibility to the park is the most preferred factor for the social interaction. Privacy and the security $10(50 \%)$ is another highest preference in Katubedda park. Not preferred factor for selecting park for social interactions in Katubedda is the spatial arrangement (availability of open spaces, naturalistic areas, play areas \& shady trees) which has 3(15\%). In Kelimadala users responded that not preferred factor is facilities provided (seating, sanitary, lightening and food stole facility) with frequency of 4 (8.9\%). In Diyatha, not expected preferred is the space allocation in the park (enough for per person=14 sq. $\mathrm{m}$ ) which is not for social interaction. The results interpret that the preference are vary according to selecting parks for interactions. 
Table 4, Demographic characteristics of respondents

(Source: Compiled by author, 2019 using SPSS from questionnaire survey)

\begin{tabular}{|c|c|c|c|c|}
\hline & Total sample & $\begin{array}{c}\text { Katubedda } \\
\text { walkway } \& \text { lake } \\
\text { park }\end{array}$ & $\begin{array}{c}\text { Ke limadala } \\
\text { park }\end{array}$ & $\begin{array}{c}\text { Diyatha Uyana } \\
\text { park }\end{array}$ \\
\hline \multicolumn{5}{|l|}{ Age } \\
\hline Below 12 & $7(4.2 \%)$ & $1(5 \%)$ & $2(4.4 \%)$ & $4(4 \%)$ \\
\hline $12-17$ yrs. & $26(15.8 \%)$ & $5(25 \%)$ & $6(13.3 \%)$ & $15(15 \%)$ \\
\hline $18-65$ yrs. & $102(61.8 \%)$ & $10(50 \%)$ & $30(66.7 \%)$ & $62(62 \%)$ \\
\hline $\begin{array}{l}\text { Above } 65 \\
\text { yrs. }\end{array}$ & $30(18.2 \%)$ & $4(20 \%)$ & $7(15.6 \%)$ & $19(19 \%)$ \\
\hline \multicolumn{5}{|l|}{ Gender } \\
\hline Male & $95(56.6 \%)$ & $12(60 \%)$ & $22(48.9 \%)$ & $61(61 \%)$ \\
\hline Female & $70(42.4 \%)$ & $8(40 \%)$ & $23(51.1 \%)$ & $39(39 \%)$ \\
\hline \multicolumn{5}{|c|}{ Monthly income (per capita) } \\
\hline Below 25000 & $12(7.3 \%)$ & $2(10 \%)$ & $2(4.4 \%)$ & $8(8 \%)$ \\
\hline $\begin{array}{l}25000-50 \\
000\end{array}$ & $20(12.1 \%)$ & $4(20 \%)$ & $4(8.9 \%)$ & $12(12 \%)$ \\
\hline $\begin{array}{l}51000-100 \\
000\end{array}$ & $41(24.8 \%)$ & $4(20 \%)$ & $13(28.9 \%)$ & $24(24 \%)$ \\
\hline $\begin{array}{l}\text { Above } 100 \\
000\end{array}$ & $20(12.1 \%)$ & $3(15 \%)$ & $6(13.3 \%)$ & $11(11 \%)$ \\
\hline No & $72(43.6 \%)$ & $7(35 \%)$ & $20(44.4 \%)$ & $45(45 \%)$ \\
\hline
\end{tabular}

Table 5, Frequency distribution of preferred factors for interactions (Source: Compiled by author, 2019 using SPSS from questionnaire survey)

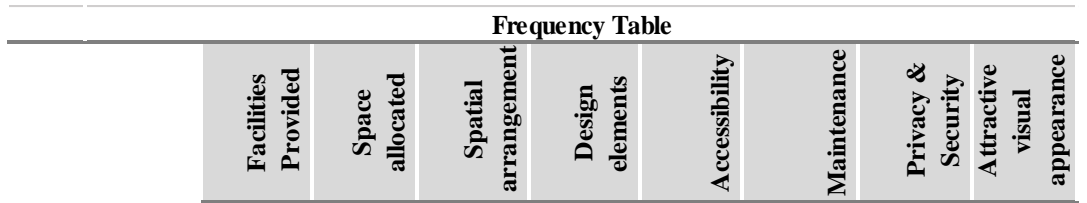

Freq Perc Freq Perc. Freq Perc. Freq Perc. Frec Perc Freq. Perc. Freq. Perc. Freq Perc.

\begin{tabular}{|c|c|c|c|c|c|c|c|c|c|c|c|c|c|c|c|}
\hline \multirow{5}{*}{ 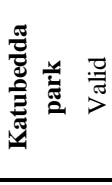 } & 1 & 1 & 5.0 & 1 & 5.0 & 3 & 15.0 & 2 & 10.0 & 0 & 0.0 & 1 & 5.0 & 0.0 & 5.0 \\
\hline & 2 & 2 & 10.0 & 3 & 15.0 & 7 & 35.0 & 9 & 45.0 & 1 & 5.0 & 2 & 10.0 & 5.0 & $\begin{array}{ll}5 & 25.0\end{array}$ \\
\hline & 3 & 13 & 65.0 & 12 & 60.0 & 9 & 45.0 & 8 & 40.0 & 9 & 45.0 & 9 & 45.0 & $\begin{array}{ll}9 & 45.0\end{array}$ & 1260.0 \\
\hline & 4 & 4 & 20.0 & 4 & 20.0 & 1 & 5.0 & 1 & 5.0 & 10 & 50.0 & 8 & 40.0 & \begin{tabular}{l|l}
10 & 50.0
\end{tabular} & $\begin{array}{ll}2 & 10.0\end{array}$ \\
\hline & Total & 20 & 100 & 20 & 100 & 20 & 100 & 20 & 100 & 20 & 100 & 20 & 100 & $20 \quad 100$ & $20 \quad 100$ \\
\hline \multirow{5}{*}{ 承 } & 1 & 4 & 8.9 & 1 & 2.2 & 1 & 2.2 & 2 & 4.4 & 0 & 0.0 & 3 & 6.6 & 0.0 & $\begin{array}{ll}1 & 2.3 \\
\end{array}$ \\
\hline & 2 & 5 & 11.1 & 9 & 20 & 10 & 22 & 9 & 20 & 2 & 4.4 & 5 & 11 & 13 & 11 \\
\hline & 3 & 23 & 51.1 & 22 & 49 & 20 & 44 & 23 & 51 & 8 & 18 & 22 & 49 & $18 \quad 40$ & $29 \quad 64$ \\
\hline & 4 & 13 & 28.9 & 13 & 29 & 14 & 31 & 11 & 24 & 35 & 78 & 15 & 33 & 47 & $10 \quad 22$ \\
\hline & Total & 45 & 100 & 45 & 100 & 45 & 100 & 45 & 100 & 45 & 100 & 45 & 100 & $\begin{array}{ll}45 & 100\end{array}$ & $\begin{array}{ll}45 & 100\end{array}$ \\
\hline \multirow{5}{*}{ 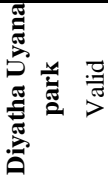 } & 1 & 4 & 4.0 & 8 & 8.0 & 6 & 6.0 & 5 & 5.0 & 0 & 0.0 & 1 & 1.0 & $\begin{array}{ll}2 & 2.0 \\
\end{array}$ & $\begin{array}{ll}2 & 2.0 \\
\end{array}$ \\
\hline & 2 & 15 & 15.0 & 23 & 23.0 & 20 & 20.0 & 10 & 10.0 & 6 & 6.0 & 7 & 7.0 & 2222.0 & 1111.0 \\
\hline & 3 & 36 & 36.0 & 45 & 45.0 & 52 & 52.0 & 62 & 62.0 & 28 & 28.0 & 28 & 28.0 & 3636.0 & 5555.0 \\
\hline & 4 & 44 & 44.0 & 24 & 24.0 & 22 & 22.0 & 23 & 23.0 & 66 & 66.0 & 64 & 64.0 & 4040.0 & 3232.0 \\
\hline & Total & 100 & 100 & 100 & 100 & 100 & 100 & 100 & 100 & 100 & 100 & 100 & 100 & $100 \quad 100$ & 100100 \\
\hline
\end{tabular}

After identifying the preferred factors the survey was targeted to get respondents comments to improve the planning potential in park planning in future to achieve more social sustainability of the place via social interactions. In Katubedda park the negative aspects need to be improved are sanitary facilities and promote diverse activities and events within the park increase the interactions. In Kelimadala Park, provide shady areas with greenery may affect for the increment of the interactions. 
Especially the children areas safety and quality have to be improved and the food prices will be manageable for achieving to everyone there. Those are the comments gained from respondents which are useful to improve the park planning potentials in Sri Lanka.

\section{Conclusion}

The key findings of the study explored that answering to the two research questions of the study. Subsequently, answer to the research question one; what are the types of social interactions in urban parks according to social network theory interpreted in user category the highest three levels interactions are occurred with adults-adults (18-65 yrs.) user category in three selected parks and the least are among youngers 12-17 yrs.) - children (below 12 yrs.) category. According to the actor types interactions are occurred more with dyad and groups in three parks rather individuals because culturally well organized activities provide more opportunities for that type of interaction behaviours. Those different types of interactions which are divided for the three levels indicated that the simple interactions convert into complex ones with not only acquaintance but also with the strangers. The social network theoretical background provides better understanding of different interaction types between the users and actors in the urban park context. These identified interaction types should be focused for increasing the future park planning potentials in Sri Lanka. Based on answer to the question two, investigate different preferred factors for the social interactions indicated that accessibility is the highest preferred factor for interactions in three parks according to place making concept derived that it is a most important component which increase social interaction in a urban place. Also the in research finding section, respondents comment for improving diverse activities and shady areas in three parks provided more interaction opportunities within the park context by achieving social sustainability of the place.

Basically, different research found that social interactions are happening in the parks. But current research findings focused more on different social interaction types in urban parks to increase the park planning potentials in Sri Lanka within the social network theoretical understanding of protocol checklist method. Further it can be elaborated that findings are useful to urban planners, designers and decision makers who are working with built environment and community for creating urban parks with social sustainability via more interaction opportunities. The future studies should refer different parks in different context to identifying the interactions types in complex ways for effectively achieving to the park planning and designing in Sri Lanka.

\section{Acknowledgement}

The authors gratefully acknowledge the participants who participated in this study.

\section{References}

Abada, T., Feng , H., \& Ram, B. (2007). Racially mixed neighborhoods, perceived neighborhood social cohesion and adolescent health in Canada. 2004-2017.

Annerstedt, M., Busse, N., \& Maaruthaveeran, S. (2013). Benifits of urban parks.The international federation of parks and recreation administration.

Ballester, O., \& Morata, A. (2001). Normas para la clasicacion de lose espacios verdes.

Cillers, E. J., \& Timmermans, W. (2015). Green place making in practice; Form of temporary space to permanent place. $2 O(3), 349-366$.

Cosco, N. G., Moore, R. C., \& Islam, M. Z. (2010). Behavior mapping: A method for linking physical activity \& outdoor design.

Dempsey, N., Bramely, G., \& Power, S. (2011). Social dimension of sustainable development. Urban social sustainability.

Hettiarachchi A, \& Silva, S. D. (2016). Factors influence to effectiveness of human behavior in designed landscape; two case studies in Sri Lanka. 
Hettige, S. T., \& Punchihewa. (2013). Changing profile of migrants workers, causes \& consequences. International Conference on Migration (ICSOM). Colombo.

Kasarda, J. D., \& Rodinnelli, D. A. (1990). Mega cities, the environment and private enterprises; Towards ecologically sustainable urbanization. 393-404.

Konau, K. S. (2016). Urban Green Spaces: Bridging cultural,.

Mitchell, J. C. (1969). The concept and use of social networks. Manchester, London: Manchester university press.

Munasinghe, M. (2019). Sustainable Sri Lanka 2030 Vision and strategic path. Colombo.

Pacion, \& Michael. (2009). Urban geography a global perspective third edition.

Perception of publicness of the public spaces with special reference to public parks in Colombo \& Sri Jayawardanapura. (2013). Colombo,Sri Lanka.

Poodeh, S., \& Vali , A. (2014). Investigating the characteristics of open space to enhance social interactions in neighborhood environment. Natural \& social science, 3(4), 148-158.

PPS (Project for public spaces). (2007). Place-making tools. Retrieved from http://www.pps.org/info/placemakingtools/casesforplaces/gr_place_feat

Puthnam, R. (2000). The collapse and revival of American community. New York.

Rafieiyan, \& Mojtaba. (2012). Urban good governance from the perspective of urban planning theories.

Rahnamatyi, Muhamad, T., \& Ashrafi, Y. (2007). The public spaces of the city and its role in the formation of civil society from perspective of urban planning.

Volker, B., Flap, H. D., \& Lindenberg, S. (2007). When are the neighborhoods communities? (Vol. 23).

Wilson, J. Q., \& Kelling, G. L. (1982, March). Broken windows; Police and neighborhood safety. Retrieved from www.theatlantic.com/politics/crime/windows.html 